\title{
Combined Transcriptomic and Metabolic Analysis Reveals the Potential Mechanism for Fruit Development and Quality Control of Rubus chingii $\mathrm{Hu}$
}

Research article

Keywords:

Posted Date: February 2nd, 2021

DOI: https://doi.org/10.21203/rs.3.rs-117873/v2

License: (1) This work is licensed under a Creative Commons Attribution 4.0 International License. Read Full License 


\section{Abstract}

The authors have requested that this preprint be withdrawn due to erroneous posting.

\section{Full Text}

The authors have withdrawn this preprint from Research Square. 